\title{
ASPECTOS FUNDAMENTALES DE LA INDEMNIZACIÓN POR EXPROPIACIÓN
}

\author{
Jaime Rojas Varas \\ Profesor de Derecho Administrativo \\ Universidad Católica del Norte (Sede Coquimbo)
}

Como es sabido, el derecho de propiedad es uno de los derechos fundamentales que la Constitución Política asegura a todas las personas. Esta garantía es una de las de mayor trascendencia de nuestro ordenamiento institucional ${ }^{1}$, encontrándose contemplada en el artículo $19 \mathrm{~N}^{\circ} 24$ de la Ley Suprema. objetivos:

El constituyente, en dicha norma, persiguió que se cumplieran los siguientes

1. Robustecer la garantía del derecho de propiedad y amparar sus atributos esenciales;

2. Admitir que la propiedad puede ser objeto de limitaciones y obligaciones para cumplir su función social, pero sin que ello pueda en caso alguno, afectar la esencia del derecho de dominio, y

3. Exigir en toda expropiación, autorizada siempre por ley, el pago de la indemnización total, al contado y en dinero, como requisito previo, anterior a la toma de posesión material del bien expropiado." ${ }^{2}$.

Lo mismo que la efectiva existencia de "utilidad pública o de interés nacional", calificada por ley, la "indemnización" constituye un requisito de la legitimidad del acto expropiatorio. Es lo que revela el citado artículo $19 \mathrm{~N}^{\circ} 24$ de la Constitución Política de la República. Ello demuestra la importancia de todo lo atinente a la indemnización en este ámbito del derecho. De acuerdo con el citado texto de la Constitución, la expropiación debe ser "indemnizada".

Como dice García de Enterría, la naturaleza jurídica de la indemnización expropiatoria está ligada a una nota fundamental, que es, su carácter preventivo que la eleva a presupuesto de legitimidad del ejercicio de la potestad de expropiar. Por eso, la

\footnotetext{
1

La Comisión de Estudios de la Nueva Constitución señaló: "el derecho de propiedad... es básico para la existencia de una verdadera democracia pues en el hecho, permite el disfrute de las libertades públicas y especialmente de la libertad política". Informe de 16 de Agosto de 1978. 2 EVANS DE LA CUADRA, Enrique. Los Derechos Constitucionales. Tomo III. $2^{\circ}$ Edición. Pag. 229.
} 
indemnización no es un efecto o consecuencia de la expropiación, sino un presupuesto de legitimidad para el ejercicio de la potestad expropiatoria.

Los principios esenciales a que debe ajustarse la expropiación no dependen de la ley formal, sino de la Carta Fundamental, a la que aquélla debe conformarse respetando su letra y sus principios. De manera que todo lo atinente al régimen jurídico de la indemnización expropiatoria se rige, esencialmente, por la letra y el espíritu del constituyente (artículo $\left.19 \mathrm{~N}^{\circ} 24\right)^{3}$, y subsidiariamente por la ley de expropiación, en cuanto esta última no vulnere la Constitución.

Una expropiación sin indemnización ${ }^{4}$, o sin adecuada indemnización, no es otra cosa que una confiscación: de ahí su antijuridicidad ${ }^{5}$.

La utilidad pública o el interés nacional no constituyen título para despojar a alguien, ni autorizan a que los habitantes sean privados de lo suyo, sin indemnización. Así resulta del citado artículo $19 \mathrm{~N}^{\circ} 24$ de la Constitución.

La Corte Suprema, en sentencia de 14 de junio de 1992, señaló en su considerando $14^{\circ}$ :

"Que la expropiación es una institución de Derecho Público por la cual el Estado o sus organismos adquieren coactivamente, a virtud de la ley, determinados bienes para dar satisfacción a fines declarados por la misma ley como de necesidad o utilidad públicas, pagándose al dueño una justa compensación.

"Elemento esencial suyo es su carácter forzoso. No requiere por tanto de la voluntad del expropiado que no puede oponerse a ella y sólo tiene derecho a exigir la indemnización correspondiente" ${ }^{16}$.

Según EVANS DE LA CUADRA, "la mayoría de la Subcomisión fue de opinión de que la Constitución debería establecer las condiciones mínimas en que la indemnización debia convenirse o fijarse por la autoridad, el plazo máximo dentro del cual debía pagarse y la reajustabilidad que compensara al expropiado respecto de la inflación. Es decir, se estimó que la Constitución debía entrar a señalar pautas mínimas respecto a la forma de determinar la indemnización y respecto a la forma de pagarla, en contra del criterio de la minoría de la Subcomisión que fue 4 partidaria de entregar al legislador competencia amplia sobre esta materia". Obra citada, pag. 272.

Los tribunales lo han sostenido de igual forma. Así: $50^{\circ}$ Que, además, por el hecho de que al propietario afectado no se le pagó suma alguna por la mencionada expropiación, resulta que se ha incurrido en una violación de la norma constitucional que dispone que "el propietario tendrá derecho siempre a indemnización..." y se le ha ocasionado a dicho expropiado un serio menoscabo de su patrimonio en beneficio de una corporación de derecho público que sin desembolso alguno ha enriquecido sus arcas. Corte de Apelaciones Presidente Aguirre Cerda, 12 de marzo de 1984. Revista de Derecho y Jurisprudencia, (RDJ), tomo 81, Vol. 2, $2^{\mathrm{a}}$ parte, sección $5^{\mathrm{a}}$, pag. 88

Se ha dicho que una expropiación sin indemnización alguna es inconcebible en un Estado de Derecho donde existe una Constitución que declara inviolable el derecho de propiedad. Una expropiación sin indemnización no es expropiación: es un despojo o una confiscación. Ver MARIEHOFF, Miguel S: "Expropiación", nota en 6 "Jurisprudencia Argentina", 1959-VI, página 256

Revista de Derecho y Jurisprudencia (RDJ), tomo 89, №22, 1992, sección 1ª, pag. 70. 


\section{¿Qué debe entenderse por "indemnización" en materia expropiatoria?}

Por tal debe entenderse el resarcimiento de todo lo necesario para que el patrimonio del expropiado quede en la situación que tenía antes de la expropiación. Tal es el principio. Por eso se ha dicho que la expropiación se resuelve en una conversión de valores: los bienes expropiados se remplazan por su equivalente en dinero?

La Ley Orgánica de Procedimiento de Expropiaciones define la indemnización en su artículo 38 como el "daño patrimonial efectivamente causado con la expropiación, y que sea una consecuencia directa e inmediata de la misma", norma que ha sido atacada en varias oportunidades por inconstitucional al agregar un requisito en su parte final no exigido por el constituyente, lo cual no ha prosperado ${ }^{8}$.

La frase final de dicho artículo, a nuestro juicio, y adelantándonos a lo que más adelante se dirá sobre el particular, sólo quiso puntualizar que los daños que deben ser indemnizados son los directos y no los indirectos o eventuales, norma similar a aquella contenida en el artículo 1558 del Código Civil.

La legislación suele y puede excluir del resarcimiento algunos valores, exclusión que será jurídicamente admisible en tanto sea razonable, es decir, en tanto no se extienda a valores esenciales integrantes del respectivo derecho de propiedad. Los valores excluidos del resarcimiento no deben integrar la consistencia jurídica del bien expropiado; de lo contrario, la exclusión será inconstitucional.

La naturaleza jurídica de la indemnización debe referírsela a tres aspectos:

a) Está regida por el derecho público y pertenece al mismo ${ }^{9}$. Esto es una consecuencia de la naturaleza jurídica de la expropiación. De ahí resulta que el régimen jurídico de la indemnización en materia de expropiación, es distinto del régimen jurídico de otros tipos de indemnización: tales diferencias radican. esencialmente, en que en materia expropiatoria la indemnización debe ser "previa" a la toma de posesión material del bien o cosa expropiado; en que el

\footnotetext{
7 Indemnizar es, conforme al Diccionario de la Lengua de la Real Academia Española, "Resarcir de un daño o perjuicio" e Indemnización es la "acción y efecto de indemnizar o indemnizarse/ 2. Cosa con que se indemniza.

$14^{2}$ Que la expropiación es una institución de derecho público por la cual el Estado o sus organismos adquieren coactivamente, a virtud de la ley determinados bienes para dar satisfacción a fines declarados por la misma ley como de necesidad o utilidad públicas, pagándose al dueño una justa compensación.

Elemento esencial suyo es su carácter forzoso. No requiere por tanto de la voluntad del expropiado que no puede oponerse a ella y sólo tiene derecho a exigir la indemnización correspondiente. Por lo mismo, como lo concluye la doctrina, lo ha declarado invariablemente esta Corte y lo dispone en forma expresa el Decreto con Fuerza de Ley $N^{2} 2.186$ de 9 de junio de 1978, el expropiante adquiere el dominio del bien expropiado por el solo ministerio de la ley, una vez que se cumplan los requisitos exigidos por la Constitución Política y la ley que rige la expropiación. Corte Suprema, 15 de junio de 1992, Jurisprudencia al Día Ediar, Tomo II pág. 603.
} 
contenido de la indemnización expropiatoria está integrado por rubros especiales, que no siempre coinciden con los que integran el contenido de otros tipos de indemnización.

b) No constituye precio. Ello es así porque la expropiación, propiamente dicha, no es un contrato, sin un acto unilateral del Estado ${ }^{10}$. Esto concuerda con el texto constitucional, pues con referencia a la expropiación, se dice que el expropiado siempre tiene derecho a ser "indemnizado" (Art. $19 \mathrm{~N}^{\circ} 24$ ). No dice que tiene derecho a ser "pagado".

c) Las cosas cambian tratándose de una indemnización fijada de común acuerdo por las partes, ya que tal acuerdo constituye una especie de contrato administrativo, donde puede considerarse que lo que recibe el expropiado es más bien un precio que una indemnización.

d) No es una deuda de cantidad o pecuniaria, sino deuda de valor, dependiente de una determinación ulterior acerca del monto; al menos originariamente no es deuda de cantidad, sino de valor, carácter que mantiene hasta el pago total de ella. Esto significa que debe considerarse la depreciación de la moneda en la medida necesaria para satisfacer la exigencia constitucional de que la indemnización cubra el daño "efectivamente causado".

e) Es renunciable una vez que el ente expropiante ha adquirido el dominio del bien, toda vez que el expropiado sólo tiene un derecho personal o crédito sobre el monto de la indemnización, que ingresa a su patrimonio como una cosa incorporal. ${ }^{11}$

La indemnización puede ser "única", si al efecto se fija una sola suma sobre la cual deben hacer valer sus pretensiones, no sólo el expropiado, sino todos aquellos que se consideren con un derecho sobre el bien que se expropia, o puede ser "divisible" (o "múltiple"), si a cada reclamante se le fija la indemnización que le corresponda.

Adoptar uno u otro sistema no es cuestión de principios sino de "política procesal". El sistema de la "unicidad", con referencia al de la "multiplicidad" o

10

Un antiguo fallo, sin embargo le da el carácter pleno de compraventa a la expropiación. Expresa que "En derecho la expropiación importa una venta forzada para fines de utilidad pública y en lo que no sea opuesta a su índole especial y a las disposiciones que particularmente la rigen, es evidente que deben entenderse incorporadas a ella las prescripciones generales de los contratos y de la compraventa civil. Corte de Valparaíso, 16 de abril de 1906. Gaceta 1907, 1² Semestre, № 173, pag. 348. En el mismo sentido, Corte Pedro Aguirre Cerda, sentencia de 28 de julio de 1986, Rol N²172-85, considerando $31^{2}$.

11

Corte de Apelaciones de Santiago, sentencia de 31 de diciembre de 1991, causa "Undurraga, Sara con Fisco". Rol N 6.444-89, publicada en Memoria del Consejo de Defensa del Estado 1991-1995, pag. 21. Ver igualmente en la misma Memoria, causa "Carlos Vial con Fisco", pag. 36 y "Benavente con Fisco", pag. 111. 
"divisibilidad", es preferible no solamente en virtud de la economía del proceso al evitar la intervención de terceros, con las consiguientes dilaciones procesales, sino principalmente porque el expropiante puede conocer desde el comienzo del juicio el total de las pretensiones del expropiado. Los que se inclinan por el sistema de la multiplicidad consideran que éste contempla mejor la situación e intereses de los terceros afectados por la expropiación. En el terreno doctrinal ambos sistemas tienen sus defensores.

La Ley Orgánica de Procedimiento de Expropiaciones ha seguido el criterio de la unicidad $^{12}$, lo que se confirma con el hecho de que existe sólo un juez competente para conocer de todos los asuntos a que se refiere esta ley, como lo indica expresamente su artículo 39 .

El monto de la indemnización no puede ser fijado o establecido por el propio expropiante, quien actúa a través de un órgano de la Administración del Estado ${ }^{13}$. Debe ser fijado o establecido definitivamente por un tercero imparcial, que en la especie es el órgano jurisdiccional ante el cual el expropiado hará valer sus derechos con todas las garantías del debido proceso ${ }^{14}$, que por regla general es el Juez de Letras Civil de Mayor Cuantía del lugar donde se encuentren los bienes, o si éstos son incorporales, el Juez del domicilio del expropiado. Si así no fuere, y la indemnización fuese fijada por la propia Administración, se violaría el principio de separación de los poderes, pues una función típicamente judicial estaría siendo ejercida por el Ejecutivo.

Empero, la ley privilegia el acuerdo de las partes y dicho acuerdo prevalecerá sobre cualquier otro procedimiento destinado a fijar la indemnización definitiva. Además, las entidades expropiantes pueden celebrar estos acuerdos no obstante cualquier prohibición o limitación establecida en sus leyes orgánicas, instrumentos constitutivos o estatutos

12

Al respecto dice su artículo 23: "Consignada a la orden del Tribunal la indemnización o la cuota que debe pagarse de contado a que se refiere el inciso primero del artículo 17, el juez ordenará publicar dos avisos a costa del expropiante conminando para que, dentro del plazo de veinte días contados desde la publicación del último aviso, los titulares de derechos reales constituidos con anterioridad al acto expropiatorio y los acreedores que antes de esa fecha hayan obtenido resoluciones judiciales que embaracen o limiten el dominio del expropiado o el ejercicio de sus facultades de dueño, hagan valer sus derechos en el procedimiento de liquidación sobre el monto de la indemnización, bajo apercibimiento de que, transcurrido dicho plazo, no podrán hacerlos valer después sobre el monto de la indemnización" 13

La ley tampoco puede imponer el monto de la indemnización por expropiación. Antiguamente, la Corte Suprema, declaró inaplicables las disposiciones legales que establecian como indemnización el valor correspondiente a la tasación del inmueble con que figura en el Rol de Avalúos para los efectos del pago de las contribuciones territoriales, más un diez por ciento de dicha tasación. Todos estos fallos se referian al inciso $3^{2}$ del artículo 73 de la Ordenanza de Construcciones de 1931. Ver RDJ, tomo 54, secc. 1ª pag. 259 y RDJ, tomo 49, secc. $1^{2}$, pag. 259, entre otros.

14

La Constitución Política de la República expresamente reconoce el derecho del administrado a recurrir a los tribunales para que en definitiva fijen el monto de la indemnización. Ver art. $19 \mathrm{~N}^{\circ} 24$, inciso tercero, parte final. 
Si la ley no contempla adecuadamente el derecho a la indemnización, resguardando equitativamente los derechos del expropiado y de la colectividad, es inaplicable por inconstitucional ${ }^{15}$.

¿Cuáles son los valores computables a los efectos de la indemnización?

De las Actas Oficiales de la Comisión Constituyente quedó clara la opinión de sus integrantes, reflejada luego en la norma que se aprobó en definitiva, de que a la persona afectada por una expropiación se le debía mantener su patrimonio indemne, esto es, libre de daño.

La discusión se centró, más bien, en la terminología que debía emplearse en la Carta Fundamental con ese objetivo, el que debía lograrse a través de la indemnización.

En definitiva, la norma que se aprobó dispone:

"El expropiado podrá reclamar de la legalidad del acto expropiatorio ante los tribunales ordinarios y tendrá siempre derecho a indemnización por el daño patrimonial efectivamente causado, la que se fijará de común acuerdo o en sentencia dictada conforme a derecho por dichos tribunales".

Conforme al artículo $19 \mathrm{~N}^{\circ} 24$ de la Constitución Política es expropiable $-\mathrm{y}$, por tanto, indemnizable- todo aquello que integre el concepto constitucional de "propiedad"16. Dentro de éste debemos comprender todos los bienes que son susceptibles de dominio privado y que están efectivamente en manos de particulares, aún cuando tengan la calidad de incorporales ${ }^{17}$.

El constituyente hace una referencia -indemnización por el daño patrimonial efectivamente causado-, pero quien se refiere al contenido mismo de la indemnización expropiatoria, como lo indicamos anteriormente, es el artículo 38 del Decreto Ley $\mathrm{N}^{\circ}$ 2.186, de 1978. Efectivamente ambos textos coinciden en que se indemniza "el daño

\footnotetext{
15

16 RDJ, tomo 70, secc. $1^{2}$, pag. 30

De acuerdo a nuestro actual ordenamiento constitucional, no existen bienes inexpropiables. Sin embargo, el artículo 9 letra a) de la Ley Orgánica de Procedimiento de Expropiaciones contempla, como fundamento de ${ }_{17}$ reclamación sobre la improcedencia de la expropiación, la inexpropiabilidad del bien expropiado, si la hubiere.

En sentencia de la Corte de Apelaciones de Concepción, confirmada por la Corte Suprema, se sostuvo sobre esta materia: "La protección que otorga la Carta Fundamental al derecho de propiedad es tan amplia que resguarda estos aspecto, ya que se desprende del tenor del artículo 19 №24 que la protección abarca no sólo las facultades que general y comúnmente confiere el dominio (uso, goce y disposición) sino que también sus atributos o facultades para dar a entender que cualquiera de ellos que se quebrante, implica un atentado contra el dominio". Se agrega que "En este concepto de "atributos" del dominio deben considerarse, a manera de ejemplos: la condición de predio riberano, tener acceso a una plaza o camino público. Estas circunstancias evidentemente son atributos y facultades de un predio con contenido patrimonial y al terreno que se le priva de ellos, le quita algo de su valor". Revista Fallos del Mes N² 372 pag. 679.
} 
patrimonial efectivamente causado", pero la ley agrega "que sea una consecuencia directa e inmediata de la misma", circunstancia que obliga a indagar cuáles son los alcances y los rubros que deberían ser considerados para la determinación definitiva de la suma a pagar.

En derecho comparado, a diferencia de nuestra legislación, expresamente se excluyen valores que no se tomarán en cuenta para establecer el monto de la indemnización, como son, por ejemplo, circunstancias de carácter personal, valores afectivos o ganancias hipotéticas, lucro cesante $y$, en el caso de inmuebles, su valor panorámico o el derivado de hechos históricos ${ }^{18}$.

No obstante el silencio, tanto de la Constitución como de la propia Ley Orgánica de Expropiaciones, existe consenso doctrinario y jurisprudencial, en que la indemnización sólo debe cubrir "el daño patrimonial efectivamente causado y que sea una consecuencia directa e inmediata de la expropiación".

De acuerdo a lo anterior, los rubros que se consideran indemnizables son los siguientes:

a) Nuestra Corte Suprema, siguiendo la doctrina vigente, ha considerado, en primer lugar, como rubro indemnizable, el valor objetivo del bien ${ }^{19}$.

b) La indemnización comprende los daños que sean una consecuencia directa e inmediata de la expropiación. Esta exigencia constitucional y legal se entiende por cuanto debe existir relación de causalidad entre el daño causado y el acto que motivó la indemnización.

Establecer cuándo el daño ha de considerarse como una consecuencia directa e inmediata de la expropiación constituye una cuestión de hecho que debe aclararse en cada caso concreto. No obstante, tanto la doctrina como la jurisprudencia mencionan diversos supuestos de daños que resultan indemnizables porque son una consecuencia directa e inmediata de la expropiación ${ }^{20}$.

\footnotetext{
18

${ }_{19}$ En Argentina se seguia este criterio en el artículo 11 de la Ley N $N^{\circ} 13.264$.

${ }^{19}$ Según Ramiro Mendoza, "...esta objetivización no puede significar, lisa y llanamente, la total exclusión del deber de reparar aquellos daños y perjuicios derivativos que tengan su origen en la operación expropiatoria, ya que debe proporcionarse aquel valor de sustitución -como advierte Oddo- que permita reponer todo lo que la expropiación le quita y recuperar, en consecuencia, todas las utilidades reales que para él suponía el objeto expropiado. En resumen, la valoración de los daños y perjuicios constituye junto a la determinación del valor del bien el total indemnizable". La potestad expropiatoria en la Constitución de 1980, En 20 AÑOS DE LA CONSTITUCIÓN CHILENA 1981-2001. / Universidad Finis Terrae. Facultad de Derecho. NAVARRO BELTRÁN, Enrique: editor. ${ }_{20}^{-12}$. Ed. - Santiago, Chile: Conosur, 2001. pag. 396

En sentencia de 31 de Enero de 1983, la Corte Suprema, en sus considerandos $6^{2}, 7^{2}$ y $8^{2}$ expresamente se refirió a este tema:
} 
1. Los perjuicios derivados de la expropiación parcial de un inmueble son indemnizables ${ }^{21}$.

2. No son indemnizables los perjuicios imprevistos e indirectos ${ }^{22}$. Esto porque los perjuicios previstos e imprevistos del Derecho Civil son los que las partes pudieron prever al tiempo de celebrar el contrato. Evidentemente aquí no se puede decir que el Estado va a pagar sólo los perjuicios que previó o pudo prever al tiempo de realizar la expropiación. Los perjuicios en este caso tienen una realidad un poco más objetiva: son los daños realmente causados al propietario con la privación del dominio de que se le hace objeto.

En cuanto a los perjuicios indirectos, evidentemente no quedan comprendidos en ningún caso en el texto constitucional ni legal, como tampoco quedan en la indemnización civil extracontractual.

"6) Que...

Ha sido la Nueva Ley Orgánica de Procedimiento de Expropiaciones-aprobada por el Decreto Ley № 2186 de 1978, la que ha venido a llenar ese vacío, al expresar en su artículo 38 que por indemnización debe entenderse, en estos casos, "el daño patrimonial efectivamente causado con la expropiación, y que sea una consecuencia directa e inmediata de la misma", definición que es dable aplicar en la especie no sólo por motivos de analogía, sino en razón de lo estatuido en la parte final del inciso segundo del artículo transitorio del referido Decreto Ley № 2186.

$7^{2}$ ) Que es un hecho de la causa que ni la hipotética pérdida de la representación de la Ford Motor ni la supresión de la estación de servicio-rubros signados a) a c) en el fundamento quinto que precede- han sido consecuencia directa e inmediata de la expropiación, toda vez que, según aparece de los documentos acompañados por las partes.

Por lo demás el recurrente no ha acreditado en forma alguna la pé rdida de la aludida representación y la supresión de la estación de servicio, si bien respecto del primer hecho aparejó una mera declaración..."

$\left.8^{2}\right)$ Que respecto de los otros dos rubros en que se dividió el lucro cesante, a saber, la supresión del servicio de RENTA CARS y la pérdida de los sueldos patronales-letras b) y d) del razonamiento quinto que precedetambién deben ser desestimados. El primero, porque no consta la supresión a que se alude y el segundo, porque el documento que lleva el $N^{2} 10$ de los guardados en custodia en el Tribunal a quo-único dato proporcionado por el expropiado sobre este particular-, consiste en un certificado del contador Félix Huespe Tapia acerca del monto de los sueldos patronales contabilizados en mayo de 1978 por don Felipe Neder Garib y Neder Hnos., no es bastante para acreditar la cesación de este típo de sueldo ni menos que, de haber ésta tenido lugar, haya sido efectivamente causada por la expropiación". En Fallos del Mes №292, pag. 7.

21

La Corte de Apelaciones de Punta Arenas, en sentencia de 29 de septiembre de 1989, fijó la indemnización definitiva, "entendiéndose en ella incluida tanto el daño patrimonial ocasionado con la substracción de su dominio de las 6,19 hectáreas expropiadas, como aquel que es una consecuencia inmediata y directa del acto. como lo es la segregación del resto del predio no afecto a expropiación en dos sectores separados entre sí y sin 22 comunicación directa entre ellos". Gaceta Jurídica N²138, pag. 15.

"Aunque el legislador no indicó con precisión la naturaleza y cuantía de estos perjuicios, siempre los vinculó con el hecho de la expropiación, y quedan excluidos, por consiguiente, los derivados de un hecho ajeno a ella. En el procedimiento de expropiación no pueden discutirse y probarse perjuicios anteriores a la expropiación misma y ajenos a ella, y derivados de una ocupación anterior del predio por parte del Fisco o terceros; y ello es sin perjuicio de que el interesado demande tales perjuicios por la vía ordinaria". Corte Suprema, 24 de mayo de 1960, RDJ. tomo 57 , secc. $1^{3}$, pag. 83. 
a) El daño que se indemniza sólo puede ser patrimonial, esto es, el que afecta el patrimonio de una persona. Para el constituyente, debe excluirse el daño moral $\left.\right|^{23}$.

b) La doctrina no acuerda indemnización por "valores afectivos", sin distinguir entre muebles e inmuebles.

Excepcionalmente hay quienes abogan por el reconocimiento del valor afectivo como rubro indemnizable en la expropiación, máxime si se tratare de una cosa "mueble".

El valor afectivo no se indemniza en estos casos porque no integra el valor objetivo del bien. Constituye un simple valor "subjetivo" que, para más, por principio general, se mantiene en el fuero interno del propietario, sin manifestaciones exteriores permanentes e inequívocas. La exclusión del valor "afectivo" como rubro a indemnizar es razonable; de ahí su juridicidad.

c) Las "ganancias hipotéticas" tampoco se indemnizan. Deben descartarse las meras posibilidades y ceñirse al destino real y efectivo del bien al ocurrir la expropiación, pues en esta medida se repara el daño real y efectivamente ocasionado con motivo del acto expropiatorio.

Así, por ejemplo, se ha fallado que si las partes concuerdan en que en un terreno expropiado se emplazaba y funcionaba un establecimiento comercial, no viene al caso colacionar hipotéticas urbanizaciones, conjuntos inmobiliarios u otros factores análogos.

Vinculado en cierta manera a las ganancias hipotéticas o supuestas, puede mencionarse al llamado "valor del porvenir", que toma en cuenta valores anteriores y posteriores a la fecha de toma de posesión material. Consideramos que el valor del porvenir es ajeno al valor objetivo, único que debe tenerse en cuenta para la indemnización, y nunca con relación a fechas posteriores a la de toma de posesión.

También debería excluirse el llamado "lucro cesante, esto es, los beneficios que el expropiado deja de percibir a raíz y con motivo de la expropiación.

Este tema no es pacífico, toda vez que si bien se acepta por la mayoría de la doctrina que el lucro cesante debe ser indemnizado, la discusión se centra en los alcances del mismo.

\footnotetext{
23

"Por eso, no tendría inconveniente para sustituir la expresión "perjuicios" por "daño patrimonial", porque con eso se excluye el daño moral". Enrique ORTÚZAR E. Presidente de la Comisión Constituyente, Actas Oficiales de la Comisión Constituyente, Sesión 167, pag. 22. En igual sentido, Jaime Guzmán en el mismo documento y página.
} 
En efecto, se ha sostenido que "La aplicación de los conceptos de daño emergente y lucro cesante requieren aquí de una observación especial. En primer término, ha de recordarse lo dicho en una ocasión anterior, en orden a que la jurisprudencia ha precisado que la indemnización comprende el valor del bien expropiado y los perjuicios que, además, se causen. Hasta la época de la dictación del Acta Constitucional №3, cuando ambos conceptos fueron aducidos en los tribunales, la jurisprudencia los consideró, resolviendo que la indemnización ha de comprender tanto el lucro cesante como el daño emergente" ${ }^{24}$

Sin embargo se ha dicho por otros que el artículo 1556 del Código Civil, que señala que la indemnización de perjuicios comprende el daño emergente y el lucro cesante, este "lucrum cessans" existe en aquellos casos en que se ha quebrantado un vínculo contractual y se ha burlado a una parte de sus derechos a obtener un lucro; pero, tratándose de una expropiación por causa de utilidad pública, en que no hay un contrato que persiga fines de lucro, no se ve claro que pueda separarse el daño emergente y el lucro cesante $\mathrm{e}^{25}$.

Dentro de la Comisión de Estudios de la Nueva Constitución se trató el tema del lucro cesante, pero se fijaron sus límites de un modo más o menos preciso. Así se señaló que "Generalmente el lucro cesante proviene de la no percepción de los frutos de la cosa, por el hecho de que el propietario ha sido privado del dominio sobre ella. Pero si el propietario se le indemniza el daño emergente, vale decir, se le reemplaza el bien -el capital por otro capital- por otro que lo deje en igualdad de condiciones patrimoniales, va a suceder que el propietario de este nuevo bien, obviamente va a extraer los frutos, los beneficios, el lucro legítimo del nuevo capital que el Estado le va a entregar y, además, si se acepta que procede el pago de la indemnización por lucro cesante, el propietario va a percibir los frutos, el lucro cesante proveniente del bien que le fue expropiado. Habría entonces una doble fuente para el propietario de percepción de lucro, de beneficios, de frutos; o podría haberla" ${ }^{26} ; 0$ bien que:

"Es evidente que si la persona se le reemplaza el bien que se le expropia por un capital que le permita obtener una determinada renta, es evidente que el monto de esa renta tiene que imputarse al supuesto lucro cesante que perdió respecto del bien que se le expropió y que antes tenía, porque, simplificando el ejemplo, la ganancia que le puede dar el nuevo capital con que se le indemniza es equivalente a la que podría obtener del bien que tenía y, en consecuencia, no ha sufrido perjuicio alguno; el perjuicio no es más que aparente, porque no hay lucro cesante; la persona para ese

\footnotetext{
24

PEÑAILILLO A., Daniel. La expropiación ante el derecho civil. Pag. 79.

${ }^{25}$ Informe del Fiscal de la Corte Suprema don PAILLÁS PEÑA, Enrique, causa Rol N 3.362-99

Sesión 166² de 13 de noviembre de 1975, Sr. Evans de la Cuadra.
} 
efecto no deja de percibir nada porque se le reemplaza por un capital que le permite adquirir otro bien". Más adelante se indica que "el señor Guzmán, manifiesta que se inclinaría por admitir el lucro cesante, en el entendido que el tribunal realmente lo va a apreciar en la totalidad de la operación y no simplemente atendiendo a lo que deja de ganar como consecuencia de la expropiación de ese bien, sin considerar lo que pasa con el capital de reemplazo que la indemnización le concede" ${ }^{27}$.

Al efecto, la jurisprudencia de la Corte Suprema ha señalado reiteradamente que "la indemnización tratándose de una expropiación, se encuentra definida legalmente en el artículo 38 de la Ley Orgánica de Procedimiento de Expropiaciones -D.L. 2186 publicado en el Diario Oficial de 9 de junio de 1978- esto es, que ella se refiera al daño patrimonial efectivamente causado con la expropiación, y que sea una consecuencia directa e inmediata de la misma. De ahí resulta que la referida indemnización no puede incluir un daño futuro, como pretende el recurrente". (Alarcón Letelier con Fisco, rol 1455-98; Gazmuri Vargas, Teresa con Fisco, rol 1456-98; Fisco con Elkins S., Bisbal Miguel, rol 3775-98, todos fallos de casación).

El valor derivado de hechos de carácter histórico ¿ Debe ser indemnizado?

La doctrina está dividida. Hay quienes excluyen el resarcimiento del valor histórico, porque consideran que la indemnización expropiatoria sólo contempla el plano estrictamente económico. Otros afirman que el expresado valor es resarcible, porque integra el valor de la cosa a la cual se vincula.

En nuestra doctrina, el profesor Peñailillo señala que la falta de precisión de los textos hace admisible la duda, pero en principio la acepta. Agrega que para la solución debe también considerarse que en ocasiones (cuando el objeto ya ha sido declarado monumento nacional) puede producirse una suerte de compensación de caracteres: por una parte, la circunstancia de ser lugar histórico puede aumentar su valor al menos ante una asociación histórica que quisiera ser dueña de ese lugar; pero, por otra, la circunstancia de ser monumento la deprecia ante la mayoría de los potenciales compradores, al quedar limitado en grado importante el derecho de dominio del particular". ${ }^{28}$

El valor histórico es distinto al valor de la respectiva cosa materialmente considerada, pero integra y acrecienta el valor de la misma. Marienhoff señala que el valor histórico -síntesis de destacables hechos del pasado- es un imponderable o intangible de carácter superior que le transmite una esencia de especial respeto al objeto respectivo.

\footnotetext{
${ }^{27}$ Misma sesión anterior, Sr. GUZMÁN ERRÁZURIZ.

${ }^{28}$ PEÑAILILLO A., Daniel. La expropiación ante el derecho civil. Pag. 76.
} 


\section{¿Es indemnizable el "valor panorámico"?}

Este valor debe ser indemnizado porque integra la consistencia jurídica del respectivo inmueble. No es lo mismo una propiedad bien situada, que una propiedad mal ubicada. Un inmueble rodeado de bellezas panorámicas es un inmueble bien ubicado. La buena ubicación es de por sí un valor.

El valor panorámico forma parte indiscutiblemente de la consistencia jurídica de la respectiva propiedad. Negar esto es desconocer una realidad de la vida diaria, o sea, que vale más una propiedad bien situada que una propiedad mal ubicada. El "ambiente" aledaño incide en el valor del inmueble.

No indemnizar el valor panorámico significa apoderarse de una parte de la propiedad $\sin$ resarcimiento, lo cual vulnera la garantía constitucional de inviolabilidad de la propiedad. El valor panorámico queda comprendido en el concepto constitucional de propiedad.

La indemnización, cualquiere fuere el tipo de bien de que se trate, debe cubrir el "valor venal" del respectivo bien. Desde luego, este valor está condicionado a la índole del bien. Dicho valor consiste en el "justo precio" que habría tenido ol bien en una libre contratación. Hay correlación entre "valor venal" y "valor objetivo".

El valor venal puede acrecentarse con el llamado "valor potencial", que es el que corresponde asignarle al bien considerando razonablemente sus aptitudes para explotarlo de acuerdo con sus características, con el resultado lógico de una más proficua obtención de valores. Pero ha de tratarse de consideraciones razonables, factibles y no de meras fantasías; de lo contrario se estaría frente a ganancias hipotéticas y no frente a un valor potencial.

Para la determinación del valor venal, especialmente tratándose de inmuebles, pueden influir los llamados "valores de zona", que son alcanzados en compraventas de tierras en zonas aledañas al inmueble que se expropia ${ }^{29}$. En este sentido, se ha dicho que "el monto de las operaciones comerciales efectivas respecto de inmuebles del sector y de similares características, evidentemente marcan un parámetro objetivable para los efectos de la fijación del justiprecio de un terreno expropiado" ${ }^{30}$

\footnotetext{
29 Se ha sostenido por algunos que "los valores de la zona representan un beneficio atentatorio al principio jurídico de que nadie puede enriquecerse sin causa. ¿ Dónde está la causa de ese beneficio excesivo y avasallador?". Ver CHISSOTTI, José E. Los valores de la zona en los juicios de expropiación, págs. 16 y 23, Buenos Aires, 1947.

30 Sentencia de 10 de septiembre de 1999. Rol № 598-1998, del Primer Juzgado Civil de Concepción, confirmada por la Corte de Apelaciones de dicha ciudad el 29 de agosto de 2000.
} 
La "plusvalía" (aumento de valor) que, a raíz de la expropiación, recibe la parte restante del inmueble expropiado ¿ debe tomarse en consideración al momento de fijar la indemnización?

Por de pronto, como lo advierten algunos expositores, esa plusvalía nunca puede compensarse con la indemnización, reemplazando a ésta. Ello es así porque la tesis contraria no suple la exigencia de que la expropiación se realice previa indemnización, la que debe tener lugar en "dinero" y no en "especie", como ocurriría en ese caso ${ }^{31}$.

Esta posición puede llevar a admitir que, en ciertos casos, la expropiación puede significar una fuente de enriquecimiento sin causa.

En cambio, la generalidad de la doctrina acepta que si la parte restante del inmueble expropiado aumenta de valor como consecuencia de la expropiación y de las obras que la motivaron, ese mayor valor, esa plusvalía, se deduzca del monto total de la indemnización, la que, por tanto, se fijará tomando en cuenta esa plusvalía. En este sentido, la Ley № 13.665 contemplaba la posibilidad de que el mayor valor perfectamente podía compensarse; además, con el objeto de que no se beneficiaran sólo algunos o se evitara esta posibilidad, se estableció un impuesto a la plusvalía o gravamen progresivo, que iba decreciendo a medida que se íba distanciando de las obras de urbanización que se hacían

Estamos de acuerdo con esta última posición en cuanto a que, si la expropiación parcial, que tiene una causa y un objetivo de utilidad pública, beneficia también particularmente al dueño de la propiedad, produciéndole un enriquecimiento, y si el mayor valor que adquiere el resto de la propiedad con motivo del destino que se le dé a la parte expropiada, es superior al monto que se regule para la expropiación, es justo y razonable que se considere compensado el precio de la expropiación con el mencionado mayor valor. En otra forma, el propietario obtendría un doble provecho: el dueño del inmueble vería valorizado su predio restante en una suma superior al monto que se fije para la expropiación, y además, recibiría en dinero el valor de la parte expropiada.

Debe hacerse presente, eso sí, que las cesiones gratuitas de terreno que deben hacerse en conformidad a la Ley General de Urbanismo y Construcciones en casos de urbanización de aquéllos, que para algunos constituyen verdaderas expropiaciones, no

31

En el momento de la expropiación, la franja de terreno que se le priva al propietario tiene un valor, y ese valor se paga, independiente de los beneficios que pueda percibir, en primer lugar, porque éstos son indeterminados y eventuales $y$, en segundo, porque si no, se podria caer en una figura que violaria el principio de igualdad ante la ley, porque se le está considerando el beneficio que el propietario expropiado va a recibir para reducir su expropiación y no se está considerando el beneficio que van a obtener los propietarios de la zona, y a los cuales no ha sido necesario expropiarles nada... El perjuicio que se indemniza es el actual, el que se produce en ese momento. Lo demás es un beneficio para la colectividad Ver Actas de la Comisión Constituyente, opinión del señor Ovalle, en sesión № 167, pag. 23. 
deben ser indemnizadas pues más que provocar un perjuicio al propietario, aumentan el valor del inmueble de manera directa ${ }^{32}$.

¿Con relación a qué fecha o época debe referirse el avalúo de un bien a los efectos de establecer el monto de la indemnización en materia expropiatoria?

En la actualidad, el sistema se rige por el sistema de los "costos" (costo histórico o de origen y costo de reproducción o de reposición), aplicable a cualquier tipo de bienes.

El criterio del costo "histórico" o de "origen" significa lo que debió invertirse "ab initio" para obtener la unidad de que se trata en estado nuevo, lista para funcionar.

El sistema de costo de "reproducción" o de "reposición" significa lo que habría que invertir para obtener, actualmente, un bien igual al de que se trata, y ponerlo en funcionamiento. Es el valor actual de mercado de esa unidad considerada nueva. Del valor presente o actual según el costo de reproducción debe deducirse lo que importe la depreciación correspondiente al estado actual del bien que se valúa.

¿Cuál de los sistemas mencionados debe aceptarse, el del costo de origen revaluado o el del costo de reproducción menos depreciación?

La doctrina está conteste en que debe aplicarse el sistema del "costo de reproducción menos depreciación". Si así no fuere, el expropiado, desde el punto de vista económico, no quedaría en la misma situación que tenía antes de la expropiación.

32

El Tribunal Constitucional, en sentencia de 15 de abril de 1997, sostuvo esta tesis señalando lo siguiente:

"Las cesiones de terreno gratuitas razonables, y éstas lo son, como se verá más adelante, inherentes a toda urbanización, lejos de constituir un daño patrimonial para el dueño procura un beneficio pecuniario para él pues el valor de los terrenos urbanizados es superior al valor de dichos terrenos sin urbanizar, incluyendo por cierto, en este último, los costos que demanda la urbanización tanto por la ejecución de las obras respectivas como aquellos que derivan de la pé rdida de superficie por las cesiones gratuitas. Esta es una realidad constitutiva de un hecho público y notorio que no se puede ignorar;

Las cesiones gratuitas se efectúan o entran en escena en el caso que el titular del dominio, por su propia y libre voluntad, resuelva urbanizar, mal podría entonces siquiera pensarse que afecten el derecho de propiedad que la Constitución le asegura, ya que resultaría absurdo que el propietario persiguiera causarse un daño patrimonial a sí mismo;

Las destinaciones gratuitas en estudio, por el contrario, robustecen el derecho de propiedad, pues persiguen, básicamente, evitar el deterioro de las propiedades vecinas, para lograr un desarrollo armónico y equitativo de las ciudades frente a aquél que, con legítimo derecho, solicita modificar el entorno urbano existente en su propio y personal beneficio; y se trata de esta manera de conciliar en forma prudente y justa los intereses personales del urbanizador con los de la sociedad toda, arbitrando los medios necesarios para que el Estado cumpla su fin primordial, cual es el bien común, mediante la creación de las condiciones sociales que permitan a todos y a cada uno de los integrantes de la comunidad nacional su mayor realización espiritual y material posible, con pleno respeto a los derechos que la Constitución asegura".

Ver RDJ tomo 94 Vol. 1, $2^{3}$ parte, sección $6^{3}$, pag. 23 
resultando así que ésta no traduciría el reemplazo de un valor por otro equivalente, sino la privación de un valor que es reemplazado por otro de menor cuantía.

El sistema del costo de origen o histórico no está de acuerdo con la normativa constitucional en cuanto a los requisitos que ha de reunir la indemnización en materia expropiatoria: dicha indemnización debe ser justa y, para ello, debe corresponder al valor actual del bien expropiado, que es lo que se le priva al titular del mismo.

¿En qué momento preciso se establece o fija el llamado costo de reposición o reproducción?

Algunos autores y tribunales estiman que este momento es el de la toma de posesión material del bien expropiado por parte del expropiante; otros consideran que debe fijarse al momento de dictarse sentencia definitiva; otros consideran el momento del pago como el que debe considerarse para fijar el valor del bien que se expropia. Finalmente, hay quienes estiman que el momento a considerar para establecer el valor dèl bien expropiado, es aquel en que se dispone y se lleva a cabo la expropiación.

En las Actas de la Comisión Constituyente se hizo referencia a este tema por parte del miembro de la Subcomisión de Propiedad Sr. Rodríguez quien insistió en la conveniencia de establecer bien claramente que los daños deben ser apreciados al momento del acto expropiatorio, y que unas son las normas para regular el monto del daño y otras las normas para establecer la forma de pago de la indemnización ${ }^{33}$. Por su parte, el comisionado Ovalle fue de la opinión de que la indemnización debía fijarse al momento en que la expropiación se consumaba, esto es, al momento en que se verificaba el pago y entrega del predio, agregando que toda variación posterior no debía ser apreciada ${ }^{34}$.

Hay jurisprudencia en diversos sentidos, pues hay fallos que se refieren al momento de emitirse el acto expropiatorio ${ }^{35}$, otros a la entrega y ocupación del bien ${ }^{36}, y$ finalmente, hay quienes lo fijan al momento del pago ${ }^{37}$.

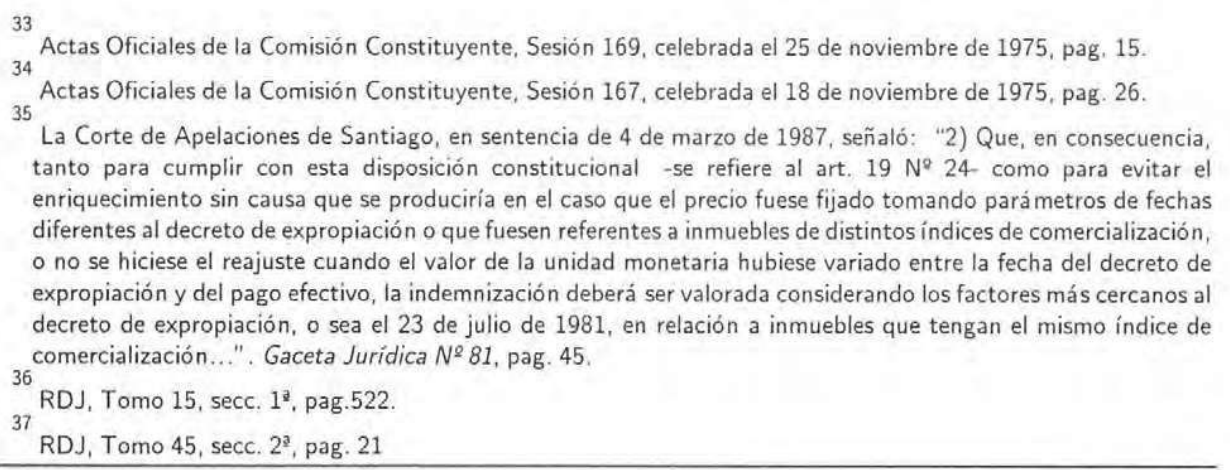


Lo cierto es que el momento al cual debe referirse el valor del bien que se expropia, puede ser, indistintamente, el de la toma de posesión material, el del pago definitivo o el de la sentencia definitiva, máxime si entre esos momentos no mediare mayor transcurso de tiempo. Sin embargo, estimamos que, de acuerdo con nuestra legislación, el momento en que el ente expropiante adquiere el dominio del bien es el que determina cuando el particular sufre el daño patrimonial, por lo que debe establecerse cuándo es la fecha en que se consigna la indemnización provisional. Desde ese día se adquiere el dominio forzoso por lo que debe concluirse que desde esa oportunidad el particular ha sufrido el daño que la indemnización ha de reparar.

De acuerdo con nuestro ordenamiento jurídico, la indemnización en materia expropiatoria tiene caracteres que actúan como verdaderos requisitos de cumplimiento ineludible.

En tal orden de ideas, la indemnización debe ser:

a) Justa. Esta comprende dos subcaracteres, que contribuyen a darle cabal significado. Para ser justa la indemnización debe ser:

$1^{\circ}$ Actual

$2^{\circ}$ Integral

b) Previa.

c) Debe tener lugar en dinero efectivo.

La doctrina, en general, menciona los expresados como caracteres de la indemnización en esta materia.

\section{a) La indemnización debe ser justa}

La expropiación trasunta una sustitución de valores: el valor del bien o cosa expropiado se reemplaza por un valor equivalente en dinero. La afirmación de que la indemnización debe ser justa, significa que debe existir una rigurosa equivalencia de valc ss entre el objeto expropiado y el monto de la indemnización. Sin esa equivalencia, la indemnización no es justa. 
La Constitución Política no dice expresamente que esta indemnización debe ser justa, pero lo imperioso de que así sea fluye implícito de la normativa de la ley suprema ${ }^{38}$.

En tanto la indemnización no sea integral y justa, la expropiación será nada más que una confiscación o un despojo. Nada hay en la Constitución que permita afirmar que el Estado, al expropiar un bien, pueda dejar sin indemnizar algún o algunos de los elementos que integran el valor del bien o cosa de que se apodera.

De acuerdo, pues, con nuestra Constitución, y a pesar del silencio de la misma, en materia expropiatoria la indemnización debe ser justa. Esto es así porque el requisito de la justa indemnización, al no existir en la Carta Fundamental un texto que lo desconozca, frente a la inviolabilidad de la propiedad asegurada por el artículo $19 \mathrm{~N}^{\circ} 24$ de la misma, constituye una garantía constitucional innominada, cuya esencia es de derecho universal, máxime en países como el nuestro donde se asegura la inviolabilidad de la propiedad, sin excepción.

La expropiación jamás puede ser motivo u ocasión de lucro para alguna de las partes, expropiante o expropiado. En el proceso expropiatorio cada parte debe recibir un valor "equivalente". Si así no fuere, no se habría respetado el principio de que la indemnización debe ser integralmente justa, ya que entonces una de las partes habría lesionado o perjudicado a la otra. En la expropiación se opera una conmutación de valores.

Ya en la Subcomisión de Propiedad se dejó constancia que es equitativo para el afectado que se le indemnicen los perjuicios y que quede indemne; pero se consideró por don Enrique Evans "que no es equitativo para la comunidad que la indemnización del perjuicio pueda implicar una eventual fuente de lucro para el afectado, a costa de la comunidad" $^{39}$.

b) La indemnización debe ser actual. Esto es un complemento de la calidad de justa que debe revestir la indemnización.

Conforme a ello el expropiado debe ser resarcido del valor que tiene el respectivo bien al ser éste transferido al expropiante.

38

La Subcomisión de Propiedad en forma unánime "dejó constancia de que la exclusión de los vocablos "equitativa". "justa" o "compensatoria" no implica la intención de significar que la indemnización no deba revestir esas características, sino que solamente tiene por objeto evitar cualquier vaguedad que su empleo pudiera originar, y para dejar establecido que la indemnización comprende todos los perjuicios reales sufridos por el propietario, incluyendo el lucro cesante, sin que pudieren restar objetividad al monto de la indemnización". En Anexo de Documentos de la Sesión 148, celebrada el 26 de agosto de 1975, pag.76.

39

Actas Oficiales de la Comisión Constituyente, Sesión 166, jueves 13 de noviembre de 1975, pags. 19 y 20. 
Corolario de lo anterior, es que el valor a considerar no es el costo de origen o histórico, sino el del costo de reposición o reproducción.

c) La indemnización debe ser integral. Esto se refiere al contenido de la indemnización. Se trata igualmente de un complemento de la calidad de justa que debe revestir la indemnización. Esta, para ser justa, debe ser integral.

Como consecuencia de que la indemnización debe ser integral, esta debe incluir o comprender todo aquello que integre la consistencia jurídica del bien que se expropie ( vgr. Intereses, valor de la moneda), no pudiendo ser disminuida mediante deducciones improcedentes (vgr. Impuestos, indisponibilidad del bien).

La indemnización será integral cuando ella trasunte efectivamente un equilibrio de valores entre el bien objeto de la expropiación y lo que en definitiva recibirá el expropiado por la privación de dicho bien.

El patrimonio del expropiado debe permanecer inalterado.

d) Otro de los caracteres de la indemnización en materia expropiatoria es que ella debe ser "previa" a la transferencia material de la propiedad al expropiante

Trátese de un carácter que surge de una expresa disposición constitucional: el artículo $19 \mathrm{~N}^{\circ} 24$ de la Carta de 1980, en cuyo mérito la toma de posesión material del bien expropiado tendrá lugar previo pago del total de la indemnización, la que, a falta de acuerdo, será determinada provisionalmente por peritos ${ }^{40}$. La diferencia sustancial, en este aspecto, con la norma del Acta Constitucional № 3, estriba en que ésta, también consideraba el pago en dinero efectivo, de inmediato, pero, enseguida establecía dos alternativas: la primera decía que el pago podía hacerse "en un plazo máximo de cinco años en cuotas iguales, una de las cuales se pagará de contado y el saldo en anualidades a partir del acto expropiatorio mediante la entrega de pagarés del Estado o garantizados por éste". La segunda expresaba "en casos calificados en que el interés nacional lo exija, la ley podrá ampliar este plazo hasta diez años".

Cuando la Constitución exige que la indemnización sea previa a la toma de posesión material, se refiere a la oportunidad en que debe efectuarse el pago, pero no al

\footnotetext{
40

"Acerca de la oportunidad y modo en que el expropiador tomará posesión material del bien expropiado, advirtió que aún cuando no se ha formado un criterio definitivo, cree que, en general, podría establecerse que la ley determinará la forma y ocasión en que la entidad expropiante tomará posesión material de la cosa y que en ningún caso tal hecho pueda constituir la desaparición de alguna de las pruebas que sea necesario allegar para fijar el monto de la indemnización. Explicó que esta última exigencia la plantea porque generalmente después de la toma de posesión material, la casa expropiada es destruida o demolida, haciéndose imposible determinar las características que tenía con anterioridad. (José María Eyzaguirre, Informe de la Subcomisión de Propiedad, inserto en las Actas Oficiales de la Comisión Constituyente, Anexo de Documentos, sesión 148, pag. 50.
} 
contenido de la misma. Ello considerando que, a falta de acuerdo de las partes, su determinación provisional corresponde a peritos designados por la autoridad administrativa en conformidad al artículo 4 de la Ley Orgánica de Procedimiento de Expropiaciones, encontrándose facultados tanto expropiante como expropiado para reclamar sobre el monto provisional fijado a través de la acción prevista en el artículo 12 de la misma ley.

La indemnización previa debe serlo con relación a la toma de posesión por parte del expropiante, constituyendo una garantía constitucional a la inviolabilidad de la propiedad. Un antiguo tratadista dijo que el propietario no puede ser privado a la vez de su bien y del precio correspondiente.

Una vez fijado el monto definitivo de la indemnización, nuestros tribunales han establecido que su pago debe efectuarse conforme a las normas del juicio de hacienda, cuando el expropiante es el Fisco.

e) Finalmente, otro carácter de la indemnización en materia expropiatoria es el relacionado a cómo debe satisfacerse o pagarse aquélla

Dicha indemnización debe pagarse en "dinero efectivo" al contado, salvo conformidad del expropiado para que le sea pagada en otra forma, por ejemplo, en títulos públicos ${ }^{41}$. Si el expropiante ofreciere otro objeto en lugar de dinero y el expropiado aceptare, podría configurarse una dación en pago.

Se explica que dicha indemnización deba ser pagada en dinero efectivo, porque la expropiación apareja para el expropiante la "obligación" de indemnizar, lo que ha de efectuarse en dinero (moneda) ya que sólo éste, por principio, extingue las obligaciones con fuerza de pago.

Según nuestra Constitución, salvo conformidad del expropiado, la referida indemnización no puede tener lugar en especie, ni mediante títulos, bonos o papeles del Estado. Semejante forma de pago -que tiene caracteres de una permuta forzada- no puede ser impuesta ni es la manera normal de extinguir obligaciones.

Antes de terminar lo relativo a la indemnización en materia expropiatoria corresponde hacer referencia a la "prescripción" de la acción para hacerla efectiva. ¿Dentro de qué lapso se prescribe la acción del propietario del bien o cosa de que se apropió el Estado, para exigir de éste el pago de la "indemnización" correspondiente?

\footnotetext{
41

La Corte Suprema, en sentencia de 4 de julio de 1956, declaró contrario a la Constitución de 1925, antes de sus reformas, el inciso $2^{\circ}$ del artículo 15 del DFL №224, de 1957 , antigua Ordenanza General de Construcciones, que autorizaba a las Municipalidades para acordar plazo para el pago de las expropiaciones.
} 
Cabe señalar, en primer término, que la acción a intentar por el expropiado es "personal", y en modo alguno "real", pues, existiendo una ley que declare de utilidad pública o de interés nacional al respectivo bien o cosa, el propietario de éste no puede pretender que dicho bien o cosa le sea devuelto por el Estado: sólo pu-de reclamar el pago de la pertinente indemnización.

La acción para reclamar judicialmente del monto de la indemnización provisional, de acuerdo al artículo 12 de la Ley Orgánica de Procedimiento de Expropiaciones, puede intentarse desde la notificación del acto expropiatorio hasta el trigésimo día siguiente a la toma de posesión material del bien expropiado ${ }^{42}$.

En casos diferentes al reclamo del monto provisional, como pormenores respecto a intereses o reajustes, tratándose de una acción personal, en tanto no exista una norma que expresamente contemple la prescripción, ésta se regiría por la norna general aplicable a las acciones ordinarias: Código Civil, artículo 2.515, que fija dicho término en cinco años. Ello considerando que, de acuerdo al artículo 2497 del mismo Código, inserto dentro de las reglas comunes a toda prescripción, éstas se aplican igualmente a favor y en contra del Estado. ${ }^{43}$

42

Dicho término se cuenta en su extinción desde la "toma de posesión material" y no desde que ella se insta o se ordena, ya que esta última situación, reglamentada en el artículo 21 del Decreto Ley $N^{2} 2186$ es diferente al hecho material referido en el artículo 12 de ese cuerpo legal y aquél tiene relevancia, precisamente para los fines que la misma disposición señala. Así, Corte de Apelaciones de Concepción, sentencia de 27 de abril de 1992, en 43 Gaceta Jurídica $N^{2} 150$, pag. 130, considerandos $3^{2}$ y $5^{\circ}$.

La Corte Suprema ha señalado en el fallo publicado en RDJ tomo XXVII, secc. $1^{2}$ pag. 240 que "La prescripción obedece a una consideración de orden público que no desconoce ni se aparta de los principios de justicia que inspiran los regímenes del derecho y de la Ley", sentando así la doctrina que la prescripción extintiva es de orden público, aplicable por tanto, a toda situación jurídica, salvo que la ley expresamente declare la imprescriptibilidad como se desprende del art. 26 de la Ley sobre Efecto Retroactivo de las Leyes. 